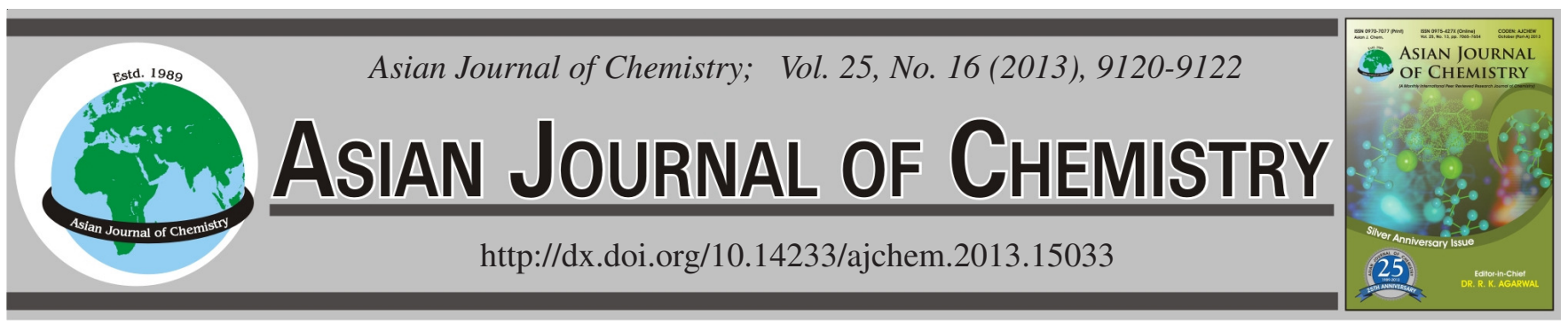

\title{
Crystallization Behaviour of Poly(L-lactic acid)/ Poly(ethylene oxide) Crystalline/Crystalline Blends
}

\author{
X. LiU, J. Zhu*, X.D. Gong and L. CAO
}

Chongqing Key Laboratory of Micro/Nano Materials Engineeing and Techonolgy, Chongqing University of Arts and Science, Chongqing, P.R. China *Corresponding author: Fax: +86 23 61162725; Tel: +86 23 61162732; E-mail: jiangzhu415@163.com

\begin{abstract}
Crystallization behaviour of a typical crystalline/crystalline blend, poly(L-lactic acid) (PLLA)/poly(ethylene oxide) (PEO), during slow non-isothermal crystallization was investigated by polarized light microscope connected with a THMS600 hot-stage and fourier transform infrared spectroscopy (FT-IR). The polarized light microscopic results indicated that the PLLA/PEO (50/50) blend produced the comparatively looser, bigger and coarser spherulites due to the formation of the interlamellar or interfibrillar structures. The FT-IR results displayed that the subtle wavenumber shift was observed in the spectra of the (50/50) blend locating at $1086 \mathrm{~cm}^{-1}$ and the intensity of the peaks at 1061,1755 and $1383 \mathrm{~cm}^{-1}$ altered to some extent, suggesting that the crystallization of the one component in the blend may be influenced by the other constituent.
\end{abstract}

Key Words: Poly(L-lactic acid), Poly(ethylene oxide), Crystalline/crystalline, Crystallization.

ᄂ - - - - - - - - - - - - - - - - - - - - - - - - -

\section{INTRODUCTION}

The blending of polymers is a powerful and economical way to produce new polymeric materials with a variety of properties. Based on the crystallizability of two constituents polymer blends can be divided into amorphous/amorphous, amorphous/crystalline blends and crystalline/crystalline blends. The blends in which both components are crystalline polymers have been extensively reported because of the formation of the multi-scale and multi-morphological structures by the varied crystallization condition, furnishing an effective route to control the polymer structures and to finally improve the materials performance ${ }^{1-3}$. In general, the blend that the two components were miscible in non-crystalline state (amorphous state, melt state or solution) and melting points between the constituents had a large difference was a kind of typical crystalline/crystalline polymer blend which have been received much concern, such as poly(butylene adipate-co -butylene succinate) (PBAS)/PEO ${ }^{4}$, poly(ethylene succinate) (PES)/ poly(ethylene oxide) $(\mathrm{PEO})^{5}$, polyoxymethylene $(\mathrm{POM}) / \mathrm{PEO}^{6-8}$, poly(vinylidene fluoride) (PVDF)/PBSA ${ }^{9}, \mathrm{PVDF} / \mathrm{poly}(1,4-$ butylene adipate) $(\mathrm{PBA})^{10}$ etc. In this system, the two components crystallized sequentially, that is, the high- $\mathrm{T}_{\mathrm{m}}$ phase first crystallized and then the low- $\mathrm{T}_{\mathrm{m}}$ one crystallized in the pre-existing crystals at lower temperature, favourable to form the interlamellar, interfibrillar or interspherulitic structures $^{4-10}$.
Poly(L-lactic acid)/PEO blends in which both constituents are well crystallizable polymers possess a pretty good compatibility in the amorphous state ${ }^{11}$. There is a gap between the crystallization temperatures of the components, about $120^{\circ} \mathrm{C}$ for poly(L-lactic acid) (PLLA) and $45^{\circ} \mathrm{C}$ for poly(ethylene oxide) (PEO), which is favourable to achieve the separate crystallization of PLLA and PEO in the blend, leading to the alteration of the crystalline morphology of the PLLA. This might be in favour of the improvement of the performance of PLLA. It is well-known that PLLA, a complete biodegradable and environmental friendly polymer material, was prepared by renewable resources and could be degraded into lactic acid and ultimately into carbon dioxide as well as water, in accord with natural circulation and regeneration ${ }^{12}$. In the past several decades, PLLA has been widely used in biomedical, industrial and agricultural fields, etc., because of the non-toxic, excellent biocompatibility, absorbability and degradability and so on. However, PLLA still has some drawbacks like the low thermal deformation temperature $\left(55-58^{\circ} \mathrm{C}\right)$, poor toughness and low impact strength, etc. ${ }^{13}$.

According to some literatures, in the POM/PEO blend ${ }^{6-8}$ the PEO crystal resided in the POM spherulties so as to form the interlamellar and interfibrillar structures which might be the reason for the improvement of friction and wear properties; in the $\mathrm{PVF}_{2} / \mathrm{PBA}$ blend ${ }^{14}$ the $\mathrm{PBA}$ phase could dispersed within the spherulitic bondaries of the PVF causing the fomation of the interspherulitic structure, as a result of the enhancement 
of the mechanical behaviour of the material. Therefore, in this paper, we attempted the method of the PLLA/PEO crystalline/ crystalline system to regulate the crystalline structure of PLLA, which may be benifical to improve the toughness.

\section{EXPERIMENTAL}

Poly(L-lactic acid) (4032D) was a product of Nature Works, USA. PEO with Mn 500,000 was supplied by Shanghai Jichen Chemical Industry Co., Ltd., China. 1,2-Dichloroethane was a product of Chengdu Kelong Chemical Reagent Company, China and used directly.

General procedure: Neat poly(L-lactic acid), neat poly(ethylene oxide) and the PLLA/PEO (50/50) blend in weight ratio of PLLA to PEO were dissolved in the mutual solvent 1,2-dichloroethane at room temperature $\left(20^{\circ} \mathrm{C}\right)$ in three beakers. The initial polymer solution concentration was 0.01 $\mathrm{g} / \mathrm{mL}$. The solvent continued to evaporate in a controlled air stream for $48 \mathrm{~h}$ at room temperature. The resulting samples were further dried in vacuum at room temperature for 3 days to remove 1,2-dichloroethane completely.

Detection method: Polarized light microscope (PLM): The crystalline morphology of samples was observed with polarized light microscope (PLM) (Leica DM2500p) connected to a Linkam THMS600 hot-stage (Linkam Scientific Instruments Ltd., UK) and a Pixelink (PL-A662) camera. The samples were heated from room temperature to $200{ }^{\circ} \mathrm{C}$ at a rate of 30 ${ }^{\circ} \mathrm{C} / \mathrm{min}$ and kept the temperature for $5 \mathrm{~min}$ to eliminate any thermal history. Then the samples were cooled to room temperature at a rate of $5{ }^{\circ} \mathrm{C} / \mathrm{min}$, The non-isothermally crystallized morphology of the PLLA and the PEO of PLLA/PEO blends was recorded in its own crystallization region. Fourier transform infrared spectroscopy (FTIR): The FTIR spectra of the samples after they were characterized by the PLM connected with the hot-stage were carried out by a FTIR spectrometer (ThermoFisher Corp., Nicolett 6670, USA), using infrared attenuated total reflection (IRATR) and operating in the wavenumber range $4000-600 \mathrm{~cm}^{-1}$ with a $4 \mathrm{~cm}^{-1}$ resolution and 32 scanning times.

\section{RESULTS AND DISCUSSION}

Fig. 1 displays the slow non-isothermal crystalline morphology of neat PLLA and the PLLA of PLLA/PEO (50/50) blend as well as neat PEO. Obviously, neat PLLA did not form spherulites with the clear Maltese-cross extinction patterns, only plentiful fragmentary crystals appearing in Fig. 1a, while neat $\mathrm{PEO}$ produce relatively perfect, compact and large spherulite (Fig. 1c), far more than that of neat PLLA, due to the large different crystallizability between PLLA and PEO macromolecular chains. In the PLLA/PEO (50/50) blend, the PLLA phase could yield comparatively loose and big spherulites, the size between that of neat PLLA and neat PEO spherulites. The possible reason was that in the PLLA/PEO blend the two consituents had a good compatibility in the amorphous state ${ }^{11}$ and they crystallized sequentially so that the PLLA partially crystallized around $120^{\circ} \mathrm{C}$ while PEO was still in the melt and well mixed with the amorphous PLLA, causing that during the non-isothermal crystallization of the PLLA, the PEO melt was enwrapped in the pre-existing PLLA crystals, that is,
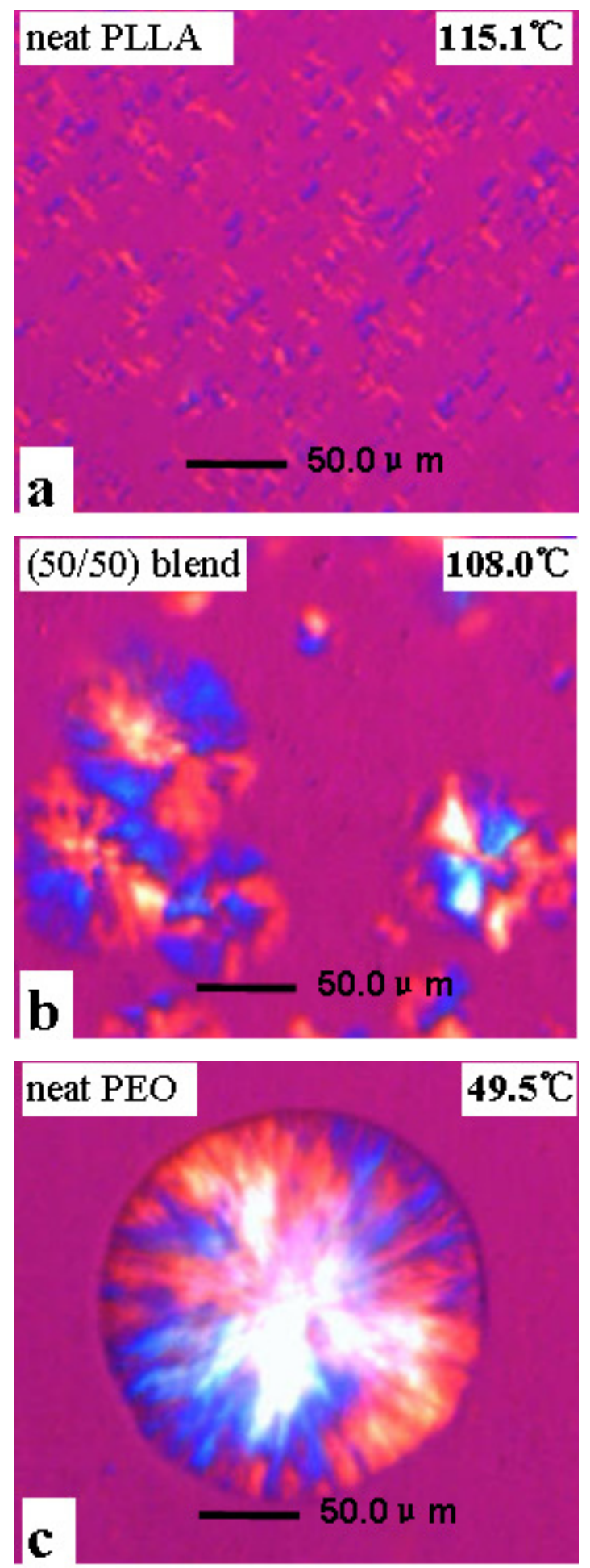

Fig. 1. Polarized light micrographs of neat PLLA and the PLLA of the PLLA/PEO (50/50) blend during the non-isothermal crystallization of the PLLA at a cooling rate of $5{ }^{\circ} \mathrm{C} / \mathrm{min}$ as well as neat PEO during its non-isothermal crystallization at the same cooling rate. The shown temperature was the corresponding crystallization temperature

dispersed within the PLLA interlamellar or interfibrillar regions. Finally, the interlamellar or interfibrillar structures could be formed in the PLLA/PEO blend, which was in good agreement with some typical crystalline/crystalline polymer blends that could form the interlamellar and interfibrillar structures, such as PBAS/PEO ${ }^{4}, \mathrm{PES} / \mathrm{PEO}^{5}, \mathrm{POM} / \mathrm{PEO}^{6-8}, \mathrm{PVDF} /$ 
PBSA $^{9}$ etc. Thus, in the PLLA/PEO (50/50) blend, the PLLA spherulites became comparatively looser, larger and coarser. Furthermore, the formed interlamellar and interfibrillar structures that the soft phase (the PEO crystals) dispersed within the tough phase (the PLLA crystals ) might be the theoretical foundation for the improvement of the toughness of PLLA. The detailed studies of the mechanical properties of the PLLA/ PEO blend will be reported later.

Fig. 2 shows infrared attenuated total reflection (IRATR) spectra of neat PLLA, neat PEO and the PLLA/PEO (50/50) blend after they were non-isothermally crystallized slowly at the cooling rate of $5^{\circ} \mathrm{C} / \mathrm{min}$, in the range of $1800-600 \mathrm{~cm}^{-1}$. As for neat PEO, the peaks occurring at 1360, 1342 and 1095 $\mathrm{cm}^{-1}$ were the characteristic peaks for the extended chain crystals (ECC) of PEO as well as the peak at $1061 \mathrm{~cm}^{-1}$ ascribed to the $\mathrm{C}-\mathrm{O}$ and $\mathrm{C}-\mathrm{C}$ stretching bands was also the characteristic peak for the floded chain crystals (FCC) and the extended chain crystals of $\mathrm{PEO}^{15,16}$. For neat PLLA, the peaks appearing in 1752 and $1383 \mathrm{~cm}^{-1}$ were the characteristic peaks for the PLLA crystals and the peaks in the region of $1000-1150 \mathrm{~cm}^{-1}$ including 1082 and $1044 \mathrm{~cm}^{-1}$ were assigned to the $\mathrm{C}-\mathrm{O}-\mathrm{C}$ and $\mathrm{C}-\mathrm{CH}_{3}$ stretching vibration bands ${ }^{17,18}$. Obviously, in the spectra of the PLLA/PEO (50/50) blend, the characteristic peaks of the PEO crystals (i.e., 1360, 1342, 1086 and $1061 \mathrm{~cm}^{-1}$ etc.) and those of the PLLA crystals (i.e., 1755 and $1383 \mathrm{~cm}^{-1}$ etc.) all appeared relatively clearly as shown in Fig. 2. Based on the comparison of the three curves, there was no new peak in the spectra of the (50/50) blend except all peaks of the PLLA and the PEO, which indicated that the co-crystal structure could not be formed in the blend. While it was still interesting to point out that the peak locating at $1086 \mathrm{~cm}^{-1}$ was overlapped by two peaks of the PEO at $1095 \mathrm{~cm}^{-1}$ and the PLLA at $1082 \mathrm{~cm}^{-1}$ i.e., the subtle wavenumber shift was observed in the spectra of the $(50 / 50)$ blend, the peak at $1061 \mathrm{~cm}^{-1}$ was much small and

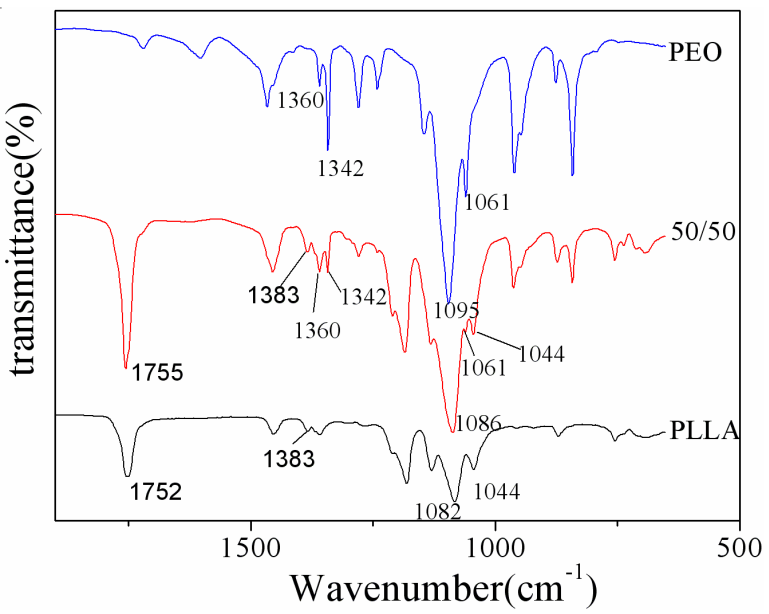

Fig. 2. Fourier transform infrared attenuated total reflection spectrum of neat PLLA, neat PEO and the PLLA/PEO (50/50) blend after the non-isothermal crystallization at the cooling rate of $5^{\circ} \mathrm{C} / \mathrm{min}$ the intensity of two peaks at 1755 and $1383 \mathrm{~cm}^{-1}$ became stronger but do not weaken with the decrease of the PLLA content. The possible reason was that the interaction between the PLLA macromolecules and the PEO ones caused that the ECC and FCC of the PEO might be affected by the PLLA phase as well as the conformations of the $\mathrm{C}-\mathrm{O}-\mathrm{C}$ or $\mathrm{C}-\mathrm{CH}_{3}$ stretching vibration bands of the PLLA macromolecules might alter to some extent, probably leading to the change of the crystallization of the PLLA phase. So the crystallization of the one component may be influenced by the other constituent.

\section{Conclusion}

In the PLLA/PEO (50/50) blend, the PEO melt resided into the pre-existing PLLA crystals causing the formation of the interfibrillar or interlamellar structures, which leaded to the comparatively looser, bigger and coarser spherulites. Due to the interaction between the PLLA macromolecules and the PEO ones, the crystallization of the one component in the blend may be influenced by the other constituent.

\section{ACKNOWLEDGEMENTS}

This work was financially supported by (1) the Openingproject Fund for Chongqing Key Laboratory of Micro/Nano Materials Engineeing and Techonolgy (KFJJ1105); (2) the Local Fund for ChongQing University of Arts and Sciences (R2012CH08); (3) the Opening-project Fund for Chongqing Key Laboratory of Micro/Nano Materials Engineeing and Techonolgy through contract grant number: KFJJ1209.

\section{REFERENCES}

1. L.Z. Liu, B. Chu, J.P. Penning and R.S.J. Manley, Macromolecules, 30, 4398 (1997).

2. W.B. Liau, S.H. Tung, W.C. Lai and L.Y. Yang, Polymer, 47, 380 (2006).

3. H.J. Chiu, H.L. Chen and J.S. Lin, Polymer, 42,5749 (2001).

4. T. Ikehara, H. Kimura and Z.B. Qiu, Macromolecules, 38, 5104 (2005).

5. J.M. Lu, Z.B. Qiu and W. Yang, Macromolecules, 41, 141 (2008).

6. X. Liu, S.B. Bai and Q. Wang, J. Macromol. Sci. Phys., 51, 642 (2012).

7. X. Liu, S.B. Bai and Q. Wang, J. Polym. Res., 19, 9787 (2012).

8. X. Liu, S.B. Bai and Q. Wang, Polym. Mater. Sci. Eng., 27, 90 (2011).

9. Z.B. Qiu, C.Z. Yan, J.M. Lu and W.T. Yang, Macromolecules, 40, 5047 (2007).

10. J.P. Penning and R.S. John Manley, Macromolecules, 29, 84 (1996).

11. A.J. Nijenhuis, E. Colstee, D.W. Grijpma and A.J. Pennings, Polymer, 37, 5849 (1996).

12. S.Y. Lee, I.J. Chin and J.S. Jung, Eur. Polym. J., 35, 2147 (1999).

13. Y.L. Li, Y. Wang, L. Liu, L. Han, F.M. Xiang and Z.W. Zhou, J. Macromol. Sci. Phys., 47, 326 (2008).

14. J.P. Penning and R.S. John Manley, Macromolecules, 29, 84 (1996).

15. H. Scholnherr and C.W. Frank, Macromolecules, 36, 1192 (2003).

16. M. Kobayashi and M. Sakashita, J. Chem. Phys., 96, 751 (1992).

17. P.J. Pan, Z.C. Liang, B. Zhu, T. Dong and Y. Inoue, Macromolecules, 42, 3374 (2009).

18. Y. Hu, H. Sato, J.M. Zhang, I. Noda and Y. Ozaki, Polymer, 49, 4204 (2008). 